\title{
'Whatsapp' Call For Help In Medical Emergencies? A Case Report
}

Nurfatihah Alias ${ }^{1}$, Nik Nurfatin Nik Mohamad Fad'lullah Suhaimi ${ }^{1}$, Shahir Asraf Abdul Rahim ${ }^{1}$, Muhammad Rasydan Abdul Ghani ${ }^{1}$, Abdul Hadi Mohamed ${ }^{1}$

${ }^{1}$ Department of Anaesthesiology and Intensive Care, Kulliyyah of Medicine, International Islamic University of Malaysia

Presenter: Nurfatihah Alias

The ubiquity of smartphones means that it has become a major mode of communication to all including the healthcare workers. Messaging applications such as WhatsApp, Instagram, WeChat, Line and others have become the new platforms for communications in the medical field between health care workers for rapid relay of information and aid in diagnosis and management of patients. This case report describes the rare complications of local anaesthetics systemic toxicity (LAST) during regional anaesthesia. Immediate calling for help was done through Whatsapp messaging application to the group of anaesthetists and anaesthesiology medical officers as there was a poor network available for a telephone call to be made. Prompt response came from other medical colleagues within few seconds after the message was conveyed. Adequate helping hands were available immediately, thus, morbidity and mortality from the life-threatening complication was successfully avoided. Messaging applications may be one of the efficient mode of technology in the medical emergencies with the increasingly advanced smartphones in computing abilities and connectivity. In the future, developing technological advances specifically designed for communicating medical emergencies can be a good alternative in ensuring more effective and rapid communication. 